NASA Technical Memorandum 107326

AIAA-96-2736

\title{
Evaluation of Low Power Hall Thruster Propulsion
}

David Manzella and Steve Oleson

NYMA, Inc.

Brook Park, Ohio

John Sankovic and Tom Haag

Lewis Research Center

Cleveland, Ohio

Alexander Semenkin

Central Research Institute of Machine Building

Kaliningrad, Moscow, Russia

Vladimir Kim

Research Institute of Applied Mechanics and Electrodynamics

Moscow Aviation Institute

Moscow, Russia

Prepared for the

32nd Joint Propulsion Conference

cosponsored by AIAA, ASME, SAE, and ASEE

Lake Buena Vista, Florida, July 1-3, 1996

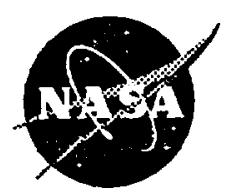

National Aeronautics and

Space Administration 



\title{
Evaluation of Low Power Hall Thruster Propulsion
}

\author{
David Manzella and Steve Oleson \\ NYMA, Inc., Engineering Services Division \\ Brook Park, Ohio 44142 U.S.A. \\ John Sankovic and Tom Haag \\ National Aeronautics and Space Administration, Lewis Research Center \\ Cleveland, Ohio 44135 U.S.A. \\ Alexander Semenkin \\ Central Research Institute of Machine Building (TsNIIMASH) \\ Kaliningrad, Moscow Region 141070 Russia \\ Vladimir Kim \\ Research Institute of Applied Mechanics and Electrodynamics, Moscow Aviation Institute \\ Moscow 125871 Russia
}

Hall thruster systems based on the SPT-50 and the TAL D-38 were evaluated and mission studies were performed. The 0.3 kilowatt SPT-50 operated with a specific impulse of 1160 seconds and an efficiency of 0.32 . The 0.8 kilowatt $D-38$ provided a specific impulse above 1700 seconds at an efficiency of 0.5 . The D-38 system was shown to offer a 56 kilogram propulsion system mass savings over a 101 kilogram hydrazine monopropellant system designed to perform North-South station keeping maneuvers on board a 430 kilogram geostationary satellite. The SPT-50 system offered a greater than $50 \%$ propulsion system mass reduction in comparison to the chemical system on board a 200 kilogram low Earth orbit spacecraft performing two orbit raises and drag makeup over two years. The performance characteristics of the SPT-50 were experimentally evaluated at a number of operating conditions. The ion current density distribution of this engine was measured. The performance and system mass benefits of advanced systems based on both engines were considered.

Introduction

Hall thruster systems have been used for performing various functions on Soviet spacecraft since 1971. ${ }^{1}$ Beginning in the early 1990's western interest in this technology has resulted in collaborative efforts to develop these systems for commercial and government applications. The primary focus has been the development of systems appropriate for North-South station keeping (NSSK) on commercial geosynchronous communication satellites. $^{2-4}$ These systems require a nominal power of approximately 1.5 kilowatts. Low power systems may be advantageous for future missions using smaller, inexpensive spacecraft. The current investigation evaluates the benefits of lower power Hall thruster systems in two representative missions. Additionally, the characteristics of a low power Hall thruster were experimentally investigated to more fully understand the potential of this technology.

Two different Hall thrusters were considered as the basis for low power Hall thruster systems, a 0.3 kilowatt (nominal) stationary plasma thruster (SPT-50) and a 0.8 kilowatt anode layer thruster (TAL D-38). Both engines were designed and built in Russia. The 0.3 kilowatt SPT-50 was developed for NASA by the Research Institute of Applied Mechanics and Electrodynamics of Moscow Aviation Institute (RIAME of MAI) and provided by the Atlantic Research Corporation/International Space Technology, Inc. ${ }^{5}$ The 0.8 kilowatt TAL, designated the D-38, was developed by the Central Research Institute of Machine Building (TsNIIMASH) for NASA and the Ballistic Missile Defense Organization and was provided through Texas Tech University. Currently both thrusters are research-class hardware and would require additional development and qualification prior to operational use.

Two representative missions chosen to assess the efficacy of low power Hall systems based on SPT-50 and D-38 engines as advanced propulsion options for small satellite applications. The missions were North-South station keeping on board a 430 kilogram geostationary satellite and orbit raising and drag make up for a 200 kilogram low Earth orbit spacecraft. For each mission considered, the low power Hall thruster propulsion systems were compared to state-of-the-art chemical propulsion technology. In order to perform such a comparison the characteristics of the Hall thruster propulsion systems were defined. Flight systems based on $1.35 \mathrm{~kW}$ Hall thruster engines have either been qualified to western standards or are currently being evaluated for qualification. 4,6,7 Qualified low power systems are not currently available, although in some cases the components used for the higher power system may be applicable. Component masses for the low power systems 
were estimated based on available hardware where possible. Masses for the power processing units were based on high power equivalents and experimental hardware. The engine performance used for this analysis was supplied by the manufacturer.

Performance characteristics of the SPT- 50 were experimentally evaluated. The objectives of these experiments were to verify the performance of the engine at the conditions selected, investigate the performance at alternate operating conditions, and to make a preliminary assessment of the plume which has been shown to be a significant concern for potential users of the higher power Hall thrusters from an integration standpoint. 8,9 Similar tests are planned for the D-38.

\section{System Descriptions}

A Hall thruster system includes the thruster sub-assembly, the propellant system, and a power processing unit. The thruster sub-assembly is made up of the engine and cathode. The propellant system stores and delivers the xenon at the appropriate rate and pressure to the thruster. The power processing unit (PPU) converts the electrical energy supplied to the propulsion system via the spacecraft bus to the voltages and currents required by the other propulsion system components. Several other sub-systems are required to make a Hall thruster propulsion system operational. These include a structural sub-system for mechanical mounting to the spacecraft, a thermal system to dissipate the required waste heat produced during thruster operation, and a gimbal system to vector the thrust if necessary. In order to conduct a comparison of low power Hall thruster systems with other propulsion systems, the characteristics of each of these subsystems were specified. The characteristics of each subsystem were considered for both the SPT-50 and the D-38. Current state-of-art (SOA) components were identified where possible. If no SOA component was directly applicable, a component that could be adapted or developed with a minimum effort was specified. Additionally, advanced systems based on the SPT-50 and D-38 were specified based on projections.

\section{Thruster}

Two low-power Hall thrusters were considered: the RIAME SPT-50 and the TsNIIMASH TAL D-38. Photographs of each thruster are shown in Figure 1. Both engines share general characteristics and operate on the same principle as the larger engines of the same type. ${ }^{10,11}$ The -50 designation of the 0.3 kilowatt SPT refers to the outside diameter of the discharge chamber in millimeters. The engine has the required magnetic field supplied by one inner magnet coil and one outer coil. The TAL D-38 magnetic field is generated by one inner and four outer magnetic coils. The -38 designation for the TAL D-38 refers to the median diameter of the discharge chamber in $\mathrm{mm}$. Neither thruster has been life tested at this time. The manufacturers predicted lifetimes of 1000 and 1500 hour for the SPT-50 and D-38 respectively. Projected life expectancies for fully optimized designs are twice the predicted lifetimes for thrusters of the current design.
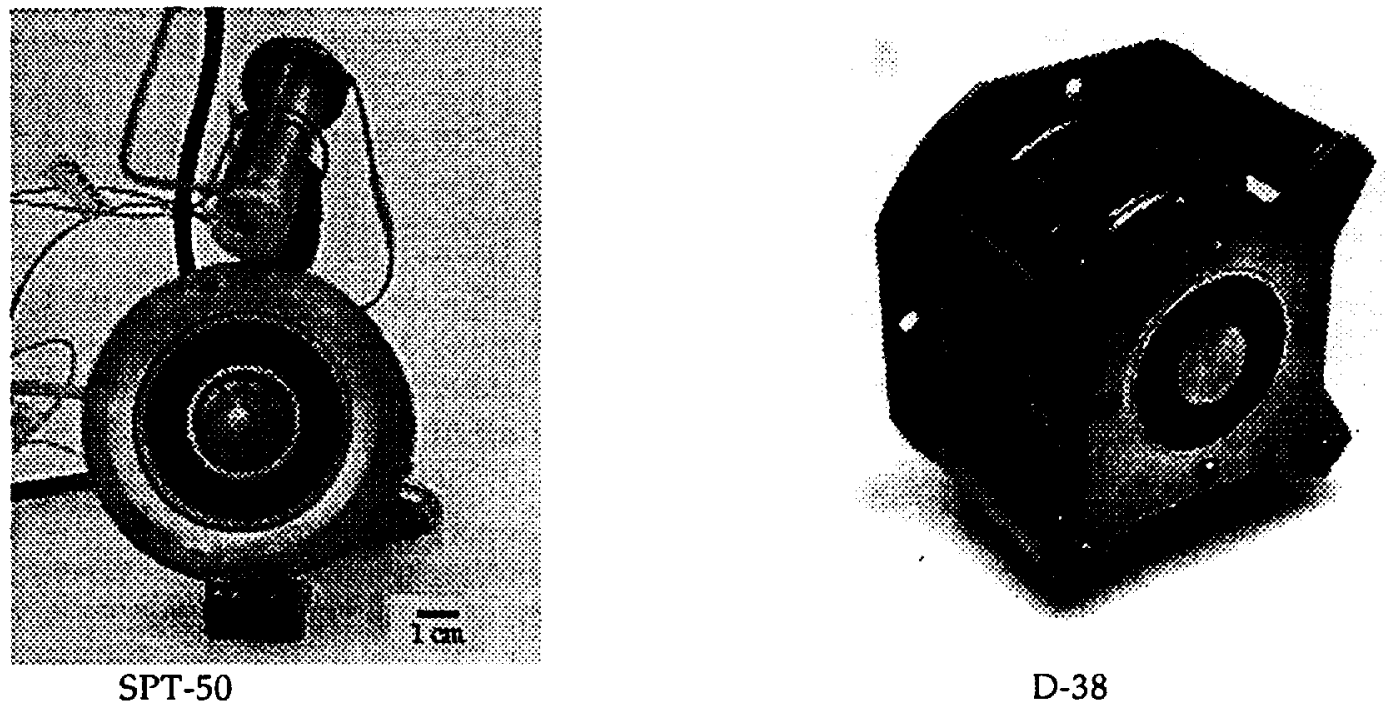

Figure 1: The 0.3 kilowatt SPT-50 and laboratory cathode from RIAME and the 0.8 kilowatt D-38 from TSNIIMASH (without required cathode).

The cathode shown in Figure 1 with the SPT-50 is a laboratory device also supplied by RIAME. It was used for an experimental evaluation of the engine. It required approximately .08 kilowatts of heater input power for the cathode emitter during operation. A propulsion system designed to use low power Hall thrusters would 
likely use a self-heated hollow cathode. As a result, the specifications for the performance of the SPT-50 include the laboratory cathode mass flow rate but neglect the cathode heater power. No cathode was supplied by TSNIIMASH. For this analysis the neutralizer cathode used by the NASA Solar Electric Propulsion Technology Application Readiness (NSTAR) program's ion engine was assumed. ${ }^{12}$ This mature design can provide emission currents between 2.1 and 3.3 Amperes at a nominal flow rate of $0.25 \mathrm{mg} / \mathrm{s}$. For a fully developed cathode designed for either engine, a cathode flow rate of $10 \%$ of the main anode flow rate was projected. This is consistent with cathode flow fractions for other Hall thrusters. ${ }^{6,7}$ Low power cathodes are currently being developed by NASA.

The SPT-50 had a mass of 0.9 kilograms including the laboratory model cathode, wiring harness, and $0.5 \mathrm{~m}$ of propellant line. While this design was not optimized with respect to mass or structural integrity, 0.9 kilograms was assumed to be the mass of a flight capable SPT-50. 0.8 kilogram was projected for a fully optimized design. This is based on a modest .06 kilogram reduction in engine mass through optimization and the development of a .1 kilogram cathode. The mass of the D-38 was unknown and was therefore estimated based on the mass of the TAL D-55.7 The mass was scaled based on the dimension of the discharge chamber. This resulted in an assumed 2 kilogram D-38 thruster sub-assembly mass for the current D-38 thruster based on 1.7 kilograms for the thruster and .3 kilograms for the NSTAR cathode. Because these estimates are based on mass optimized devices no further reduction in mass is anticipated. The differences in thruster masses is consistent with differences in the nominal input power. Table 1 contains both the current and projected characteristics for SOA and advanced versions of the D-38 and the SPT-50. Performance was provided by the thrusters' manufacturer.

Table 1: Current and Projected Low Power Hall Thruster Characteristics

\begin{tabular}{lcccc}
\hline Parameter & \multicolumn{2}{c}{ D-38 } & \multicolumn{2}{c}{ SPT-50 } \\
\hline & current & advanced & current & advanced \\
\hline Thruster Power, Watts & 766 & 766 & 310 & 310 \\
Discharge Current, Amperes & 2.52 & 2.52 & 1.05 & 1.05 \\
Discharge Voltage, Volts & 300 & 300 & 280 & 280 \\
Anode Flow rate, mg/s & 2.36 & 2.36 & 1.26 & 1.26 \\
Cathode Flow rate, mg/s & 0.25 & 0.236 & .26 & .126 \\
Thrust, mN & 45.8 & 45.8 & 17.3 & 17.3 \\
Specific Impulse, seconds & 1790 & 1800 & 1160 & 1270 \\
Thruster Efficiency & 0.51 & 0.52 & 0.32 & 0.35 \\
Lifetime, hours & 1500 & 3000 & 1000 & 2000 \\
Mass, kilograms & 2.0 & 2.0 & 0.9 & 0.8 \\
\hline \hline
\end{tabular}

Power Processing Unit

Flight representative PPUs have not been developed for low power Hall thrusters. A PPU designed for either thruster requires a minimum of two separate power supplies including a discharge supply, a nominal 300 Volt isolated, stabilized voltage source capable of supplying approximately one Ampere for the SPT-50 or approximately 2.5 Amperes in the case of the D-38, and an ignitor supply, capable of providing a short duration voltage pulse of up to a kilovolt. Depending on cathode design, a cathode heater supply may be required. It may also be advantageous to have one or two independent magnet supplies rather than running the electromagnets in series with the discharge. Other functions that would be required of the PPU are operation of the electromechanical components of the propellant feed system and command and telemetry interfaces between the spacecraft and propulsion system.

Because more information has been published regarding the design of the Loral SPT-100 PPU than other PPUs under development, this design was used as the basis for estimating the mass of lower power PPUs. Loral's partially redundant PPU has nine anode modules, two heater supplies, two magnet supplies, and two ignitor supplies. 5,13 The total mass of this PPU was $8.5 \mathrm{~kg}$. A similar PPU for the SPT-50 with no internal redundancies has a projected mass of $2 \mathrm{~kg}$. A PPU for the higher current D-38 has an estimated mass of $3.5 \mathrm{~kg}$. Both of these include a cathode heater supply. PPU efficiencies were estimated to be 0.90 .

Improvements in the design of these PPUs are likely possible. A recent 0.3 kilowatt breadboard arcjet PPU with non-optimized magnetics had a total mass of .950 kilograms and a component mass of approximately .500 kilograms. ${ }^{14}$ This PPU had voltage-current characteristics similar to what would be required for the SPT-50. A integral ignitor supply was also included. Based on this, a 1 kilogram flight PPU should be possible if the magnets are run in series with the discharge. Similar improvements may be expected for a PPU optimized for the D-38 but, because of the low level of development at this power level, a 4 kilogram estimate for a non- 
redundant configuration without a separate magnet supply was used. The efficiency values for these PPUs will likely remain near 0.90 .

\section{Propellant System}

Propellant feed systems suitable for low power Hall thruster propulsion systems can be categorized as either actively or passively controlled. This refers to the method of regulating the xenon flow rate to the engine. Active flow control allows continuous control of thruster discharge current, and therefore thruster power, as determined by the mass flow rate through the engine. A passively controlled system utilizes a fixed setpoint without feed back. Both types of flow control are currently being implemented.7,15 Actively controlled systems rely on conventional xenon flow controllers that would substantially increase the mass of the propellant system for a low power system. This may not be the case in the future, based on NASA testing of micromachined flow regulating components. However, for this investigation passive flow control was assumed.

For this study, a passively controlled propellant feed system was chosen as the current SOA with respect to mass. Such a system can be constructed from currently available, commercial flight quality hard ware. It would include two service valves, a filter, a mechanical regulator, redundant isolation valves, and an orifice assembly. The component mass for this system, which would work equally well for the SPT-50 or the D-38, would be 1.3 kilograms. Another approximately .2 kilograms would be required for plumbing between these various components in an all welded system.

An actively controlled system was chosen for the advanced system with downstream flow regulation based on the micromachined flow controller. Isolation could be provided by redundant miniaturized latching valves. The mechanical pressure regulator would be substantially reduced in size and mass because pressure variations substantially larger than tolerable by the passive system can be tolerated. An in-line filter and flow restricting orifices would also be required. The estimated mass for such a system is .8 kilograms.

The remaining component for a propulsion feed system is the propellant tank. While the size of the required tank is mission specific, for purposes of comparison, a system is sized assuming an amount of xenon equivalent to $110 \%$ of the total operational lifetime of the specified thruster. For the current SPT-50, including margin, approximately $6 \mathrm{~kg}$ of xenon is required to be delivered the rated total impulse of 62300 Newton-seconds. Approximately $15.5 \mathrm{~kg}$ of xenon with $10 \%$ margin is required for the 247000 Newton-second predicted total impulse of the D-38. A maximum temperature of $50^{\circ} \mathrm{C}$ and a maximum pressure of 2000 psia were assumed for storage of supercritical xenon to permit sizing of the storage tank. A tankage fraction of $10 \%$ was assumed for composite over-wrapped tanks with a load sharing metallic liner. This corresponds to a tank of about $20 \mathrm{~cm}$ in diameter for the SOA SPT-50 and about $27 \mathrm{~cm}$ in diameter for the SOA D-38 having a mass of .6 and 1.55 kilograms respectively. For and advanced thruster with double the operational life, twice the propellant load would be required. Ten percent tankage fractions would also apply to tanks of the size required to store this additional amount of xenon.

\section{Mechanical Structure, Thermal Control, and Gimbals}

The mechanical structure, thermal control system, and thruster gimbals all need to be considered in order to provide a realistic description of a low power Hall systems. In many cases, the appropriate design will be spacecraft specific, however, guidelines for making engineering estimates of the mass of these systems for geosynchronous spacecraft were suggested by Rawlin. ${ }^{16}$ These guidelines were used to make estimates, again for the purpose of permitting comparison. Based on these suggestions the thermal control system will have a mass of approximately 31 kilograms per kilowatt of waste heat. This corresponds to a mass of 1.1 kilograms for the SPT-50 and 2.6 kilograms for the D-38. Thruster gimbals have an estimated mass of $34 \%$ of the thruster mass and the required structure can be estimated as $31 \%$ of the sum of the thruster, gimbal, and propellant system mass (excluding the propellant and the propellant tank) plus $4 \%$ of the PPU, propellant, and propellant tank mass.

\section{System Summary}

For comparison purposes a complete summary of the component and system masses is shown in Table 2. Each system is configured with a single thruster and has the mass of propellant required to provide the maximum predicted impulse plus $10 \%$ margin. In the following section, several mission studies were performed using the characteristics of the low power Hall thruster system configured for specific missions. 
Table 2: Current and Projected Low Power Hall Thruster Sub-System Masses (in kilograms unless otherwise noted)

\begin{tabular}{lcccc}
\hline \hline & \multicolumn{3}{c}{ D-38 } & \multicolumn{2}{c}{ SPT-50 } \\
\hline Sub system & current & advanced & current & advanced \\
\hline Thruster & 2.0 & 2.0 & 0.9 & 0.8 \\
System Power, Watts & 850 & 850 & 344 & 344 \\
Feed System & 1.5 & 0.8 & 1.5 & 0.8 \\
PPU & 5.0 & 4.0 & 2.0 & 1.0 \\
Propellant & 15.5 & 30.8 & 6.0 & 11.0 \\
Propellant Tank & 1.6 & 3.1 & 0.6 & 1.1 \\
Gimbal & 0.7 & 0.7 & 0.3 & 0.3 \\
Thermal control & 2.6 & 2.6 & 1.1 & 1.1 \\
Structure & 2.3 & 2.7 & 1.2 & 1.1 \\
System dry mass & 15.7 & 15.9 & 7.6 & 6.2 \\
System wet mass & 31.2 & 46.7 & 13.6 & 17.2 \\
Total Impulse, N-sec & 247000 & 495000 & 62300 & 125000 \\
\hline \hline
\end{tabular}

\section{Mission Studies}

The impacts of low-power Hall thruster propulsion systems on two missions were considered in order to investigate the relative benefits of developing flight systems based on the D-38 and the SPT-50. North-South station keeping (NSSK) on a small $(430 \mathrm{~kg}$ ) geostationary satellite was considered as a target mission for a D38 propulsion system. A 200 kilogram, low Earth orbit spacecraft with a mission consisting of two orbit raises and drag makeup was chosen to investigate the viability of a low power Hall thruster propulsion system based on the SPT-50. These missions were chosen because the spacecraft power and the total impulse requirements were consistent with the appropriate Hall system. The required Hall thruster propulsion system components were based on the information presented above. A potential propulsion system configuration was also suggested. Each mission application compared the Hall thruster propulsion system to baseline propulsion systems. Both examples demonstrated an increase in the usable payload mass as a result of the Hall thruster propulsion system. Conversely, if the baseline payload remained unchanged, the total spacecraft mass and launch mass could be reduced through the use of the Hall system.

Small Geostationary Satellite

Large geostationary satellites continue to be an important part of the communication industry. Smaller geostationary satellites designed to serve one customer or provide a single service are also being considered. One such example is the planned Indostar 1 spacecraft. ${ }^{17}$ With a beginning-of-life (BOL) mass of 430 kilograms and an end-of-life (EOL) power of 0.9 kilowatts, the Indostar 1 is significantly smaller than other planned geostationary satellites.

Using the Indostar 1 as representative of this new class of satellites, the impact of the D-38 and advanced D-38 thrusters on reducing the wet system mass was determined. Reduction in mass would allow for an increase in the mass of the payload and support systems, a reduction in launch mass, or an increase in lifetime. A 10 year mission with a $45 \mathrm{~m} / \mathrm{s}$ NSSK budget per year is assumed. ${ }^{18}$ State-of-art $\mathrm{N}_{2} \mathrm{H}_{4}$ monopropellant ${ }^{19}$ and $\mathrm{N}_{2} \mathrm{H}_{4}$ arcjet systems ${ }^{20}$ were used for comparison. The operating parameters and system masses assumed are shown in Table 3.

Table 3: Operating parameters and propulsion system masses for a $430 \mathrm{~kg}$ geostationary satellite with either hydrazine monopropellant, hydrazine arcjet, or low power Hall thruster propulsion systems.

\begin{tabular}{lcccc}
\hline \hline Propulsion System & $\mathrm{N}_{2} \mathrm{H}_{4}$ Monopropellant & $\mathrm{N}_{2} \mathrm{H}_{4}$ Arcjet & TAL D-38 & Advanced D-38 \\
\hline Total Spacecraft mass, kilograms & 430 & 430 & 430 & 430 \\
Propulsion Dry Mass, kilograms & 23.4 & 22.6 & 32.1 & 27.1 \\
Propellant mass, kilograms & 77.7 & 43.6 & 15.4 & 15.3 \\
Propulsion Wet Mass, kilograms & 101.1 & 66.2 & 47.5 & 42.4 \\
System Power, Watts & 0 & 850 & 850 & 850 \\
$\Delta \mathrm{v}, \mathrm{m} / \mathrm{s}$ & 450 & 450 & 450 & 450 \\
Thruster Specific Impulse, sec & 230 & 450 & 1790 & 1800 \\
Gross Engine Thrust, Newtons & 4.45 & 0.119 & 0.049 & 0.049 \\
\# of thrusters & 4 & 4 & 4 & 4 \\
Cant Angle & 0 & $17^{\circ}$ & $45^{\circ}$ & $45^{\circ}$ \\
Total burn time, hours & 2.7 & 450 & 1640 & 1640 \\
daily burn time, minutes & 0.05 & 7 & 27 & 27 \\
\hline \hline
\end{tabular}


The configuration assumed for the D-38 and arcjet systems was redundant thrusters, two each on the north and south faces of the satellite and a single PPU. The D-38 thrusters were canted at $45^{\circ}$ relative to the optimal thrust direction along the north-north axis and the arcjets were canted at $17^{\circ} .21$ This is done to minimize the effect of plume impingement on the solar arrays. ${ }^{22}$ Only one thruster is operated at a time. Burns are made at opposite sides of the orbit once a day. In this way the eccentricity induced by the radial component of the single canted thruster burn is offset by the burn on the other side of the orbit. This radial thrust component also creates a longitude shift which is removed by placing the satellite in a slighter higher orbit (about $400 \mathrm{~m}$ ). ${ }^{23}$ The electric thrusters run off of the batteries while the payload uses the solar array power. ${ }^{22}$ While the added cycling may require extra batteries to ensure 10 year payload eclipse operation, this was not included in the analysis.

Each of the electric propulsion systems requires lifetimes less than those currently predicted. For the Hall system each of the two thrusters fire for approximately 14 minutes once a day. For the arcjet system, each of the two thrusters fire for approximately 3 minutes once a day. The system dry masses ranged from 23 to 32 kilograms. The arcjet and hydrazine monopropellant systems had dry masses of approximately 23 kilograms. The SOA Hall system has a dry mass at 32 kilograms and the advanced Hall system has a system dry mass of 27 kilograms. The differences in propulsion system wet masses were substantially larger. The hydrazine monopropellant system was the heaviest, with a fueled mass of approximately 100 kilograms. The arcjet system has a wet mass of 66 kilograms. The SOA Hall system has a wet mass of 48 kilograms, and the advanced Hall system has a wet mass of 42 kilograms. The greater than $50 \%$ reduction in propulsion system wet mass for the Hall system relative to the hydrazine monopropellant propulsion system, corresponds to a 50 to 60 kilogram mass savings on a 430 kilogram spacecraft. The 14 to 19 kilogram mass savings for the Hall thruster systems relative to the arcjet system was less substantial, but still significant.

\section{Small Low Earth Orbit Satellite}

A 0.3 kilowatt Hall thruster system may be suitable for a low-Earth orbiting, Earth observing or communications satellites. A modified Clementine ${ }^{24}$ satellite was chosen for a mission consisting of an initial $300 \mathrm{~km}$ to $400 \mathrm{~km}$ orbit raising maneuver to an operational orbit, drag make up at this altitude for two years, and a final orbit raise to $700 \mathrm{~km}$. The analysis was performed using an iterative routine which calculated the amount of circular orbit altitude change assuming constant drag force versus the thrusting force over a circular orbit. Shading reduced the constant thrust over the orbit by a worst case shadow fraction. The 0.36 kilowatt Clementine spacecraft had an estimated mass of 200 kilograms without the lunar propulsion module.

Three propulsion systems were considered for performing the orbit raising functions and drag makeup: a SOA SPT-50 system, an advanced SPT-50 system, and a monopropellant $\mathrm{N}_{2} \mathrm{H}_{4}$ system. ${ }^{19}$ Due to the SPT-50's limited lifetime and the separate orbit raising and drag make up propulsion requirements, two thrusters were baselined for both the SOA and the advanced system. At any time during the mission only a single thruster would be operated using the single PPU. One of the thrusters, positioned along the spacecraft body's cylindrical axis, was tasked with the orbit raising. For these burns the spacecraft was pointed in a direction tangential to the orbit. During the drag make up portion of the mission, the cylindrical spacecraft was assumed to be oriented in the nadir direction. The second thruster, positioned perpendicular to the spacecraft body axis, was then tasked with the drag make up, firing in the tangential direction at required intervals to maintain the $400 \mathrm{~km}$ orbit.

The drag acceleration on the satellite depended on the cross-sectional area perpendicular to the velocity direction, the coefficient of drag, the satellite velocity and mass, and the atmospheric density. The average satellite cross-sectional area during orbit raising was assumed to be $1.6 \mathrm{~m}^{2}$ while the cross-sectional area during nadir pointing operations was assumed to be $2.7 \mathrm{~m}^{2}$. The coefficient of drag was assumed to be 2.2 . In order to bound the impact of variation in atmospheric density with solar cycle, both average and solar max atmospheres were considered. The atmospheric density was calculated using the F10.7 index, based on the solar activity monitored by the $10.7 \mathrm{~cm}$ radio flux measured in units of $10^{-22} \mathrm{~W} /\left(\mathrm{m}^{2} \mathrm{~Hz}\right) .^{25}$ Since 1945 the solar radio flux index has varied from roughly $75 \times 10^{-22} \mathrm{~W} /\left(\mathrm{m}^{2} \mathrm{~Hz}\right)$ to $250 \times 10^{-22} \mathrm{~W} /\left(\mathrm{m}^{2} \mathrm{~Hz}\right)$. Thus, an average index of $150 \times 10^{-2} \mathrm{~W} /\left(\mathrm{m}^{2} \mathrm{~Hz}\right)$ was chosen for the average atmosphere. An index of $250 \times 10^{-2} \mathrm{~W} /\left(\mathrm{m}^{2} \mathrm{~Hz}\right)$ was assumed to represent the average atmospheric density during a solar maximum year.

The mission $\Delta V$ requirements are shown in Table 4 for each propulsion system based on the 250 and 150 F10.7 index atmospheres. The monopropellant mission assumed an impulsive Hohmann transfer. The $\Delta \mathrm{V}$ for both Hall thruster systems was higher due to continuous thrusting and the opposing drag force during the spiral trajectory. The $\Delta \mathrm{V}$ requirements for the drag makeup portion of the mission are also shown in Table 4 . For drag 
makeup the monopropellant has duty cycles of $0.016 \%$ and $0.043 \%$, for the average and solar maximum density atmospheres, respectively. The SPT-50 and advanced SPT-50s have duty cycles of $7 \%$ and $18 \%$. The drag makeup $\Delta \mathrm{V}$ for the solar-maximum atmosphere is roughly three times that of the average atmosphere due to the increase in atmospheric density. As a result, a second drag make-up thruster is included for SOA SPT-50 system when used in a solar-maximum density. This is not required for the advanced system due to sufficient thruster lifetime for the advanced SPT-50 design.

Table 4: Operating parameters and propulsion system mass for a $200 \mathrm{~kg}$ low Earth orbit satellite with either hydrazine monopropellant or low power Hall thruster propulsion system. Where two entries appear the first is for a mission with a solar maximum atmospheric density and the second corresponds to a mission with an average solar density atmosphere.

\begin{tabular}{lccc}
\hline Propulsion System & $\mathrm{N}_{2} \mathrm{H}_{4}$ Monopropellant & SPT-50 & Advanced SPT-50 \\
\hline Total Spacecraft mass, kilograms & 200 & 200 & 200 \\
Propulsion Dry Mass, kilograms & $9.3 / 6.4$ & $15.9 / 11.4$ & $8.9 / 8.0$ \\
Propellant mass, kilograms & $61.7 / 36.2$ & $14.7 / 7.9$ & $13.5 / 7.2$ \\
Propulsion Wet Mass, kilograms & $70.9 / 42.7$ & $30.7 / 19.4$ & $22.3 / 15.2$ \\
System Power, Watts & 0 & 344 & 344 \\
Total $\Delta \mathrm{v}, \mathrm{m} / \mathrm{s}$ & $828 / 449$ & $870 / 460$ & $869 / 459$ \\
$300-400 \mathrm{~km} \Delta \mathrm{v}, \mathrm{m} / \mathrm{s}$ & 57.2 & $80 / 66$ & $79 / 55$ \\
2 year drag make up $\Delta \mathrm{v}, \mathrm{m} / \mathrm{s}$ & $606.5 / 227.5$ & $620 / 228$ & $620 / 238$ \\
400-700 km $\Delta \mathrm{v}, \mathrm{m} / \mathrm{s}$ & 164.3 & $170 / 166$ & $170 / 166$ \\
Thruster Specific Impulse, sec & 230 & 1160 & 1270 \\
Engine Thrust, Newtons & 4.45 & 0.0174 & 0.0174 \\
\# of thrusters & 1 & $3 / 2$ & 2 \\
Cant Angle & $0^{\circ}$ & 0 & 0 \\
Total burn time, hours & $9 / 5$ & $2670 / 1440$ & $2530 / 1360$ \\
\hline
\end{tabular}

From Table 4 it can be seen that regardless of assumed atmospheric density, use of the SOA SPT-50 and advanced SPT-50 offers significant reductions in propulsion system wet mass. In most cases the Hall system dry mass is several kilograms heavier than the hydrazine monopropellant system dry mass. With respect to wet mass, however, the SOA Hall systems offers at 20 to 40 kilogram savings in wet mass depending on atmospheric conditions. The advanced SPT-50 provides an additional $10 \%$ mass reduction over the SOA Hall system and requires no additional thrusters. The 49 kilogram mass saving for the advanced Hall in comparison to the monopropellant system for the solar maximum density results in a $25 \%$ reduction in gross spacecraft mass.

Apparatus and Procedure

\section{Thruster Evaluation}

The tests of the SPT-50 were designed to confirm the performance indicated by RIAME and to investigate other operating points. Tests of the D-38 are currently planned. In all cases the SPT-50 thruster was operated using commercially available power supplies. A constant voltage laboratory power supply with an in-line $10 \mathrm{Ohm}$ ballast resistor was used to run the discharge. A $100 \mu \mathrm{F}$ capacitor was placed across the discharge to reduce the effect of plasma oscillations on the discharge supply. Separate dc supplies were used for the electromagnets and the cathode heater. A high voltage, low current supply was used to initiate thruster operation. The entire electrical system was allowed to float relative to ground. Typical cathode to ground voltages were -15 Volts. The thruster was run on commercially available research grade xenon having a purity better than $99.9995 \%$. A laboratory model feed system which incorporated commercially available mass flow controllers to provide the desired flow rate to the anode and cathode was used. These flow meters were calibrated before and after testing. Uncertainties in mass flow rate measurements were estimated to be $\pm 2 \%$.

Thrust was measured directly using an inverted pendulum design thrust stand that was used previously to evaluate various Hall thrusters. ${ }^{26,27}$ This instrument ${ }^{11}$ was calibrated in-situ using three weights with a mass of approximately 0.006 kilograms each. The uncertainty in the thrust measurements as determined based primarily on the zero drift was estimated to be $\pm 1.5 \%$.

The ion current density distribution was also measured to provide a basis for future integration assessments of this device. This was done utilizing an planar ion collector on the end of a $0.6 \mathrm{~m}$ arm rotated by a stepper motor driven rotary actuator. Data were taken in steps of one degree from -100 degrees to 100 degrees with respect to the thruster axis. This apparatus was also previously discussed in detail. ${ }^{28}$ All testing was conducted in a cylindrical vacuum chamber $5 \mathrm{~m}$ long by $1.5 \mathrm{~m}$ diameter. The chamber was pumped by four $0.82 \mathrm{~m}$ diameter oil diffusion pumps, a lobe type mechanical blower, and two piston type roughing pumps. The thruster was 
mounted in the center of the chamber, firing along the major axis. The xenon corrected ambient pressure, measured by an ionization gauge during testing, was $1 \times 10^{-5}$ Torr.

\section{Results and Discussion}

The SPT-50 was operated over a range of input powers from .09 to .4 kilowatts. Both thrust and ion current density distribution were measured in addition to operational parameters such as discharge current, discharge voltage, magnet currents and voltages, and the floating voltage of the cathode with respect to ground. Operation at discharge voltages between 150 and 400 Volts was investigated. Discharge currents between .4 and 1.3 Amperes were obtained by variation in the anode flow rate. The relation ship between Anode flow rate and Discharge current was found to be linear as shown in Figure 2.

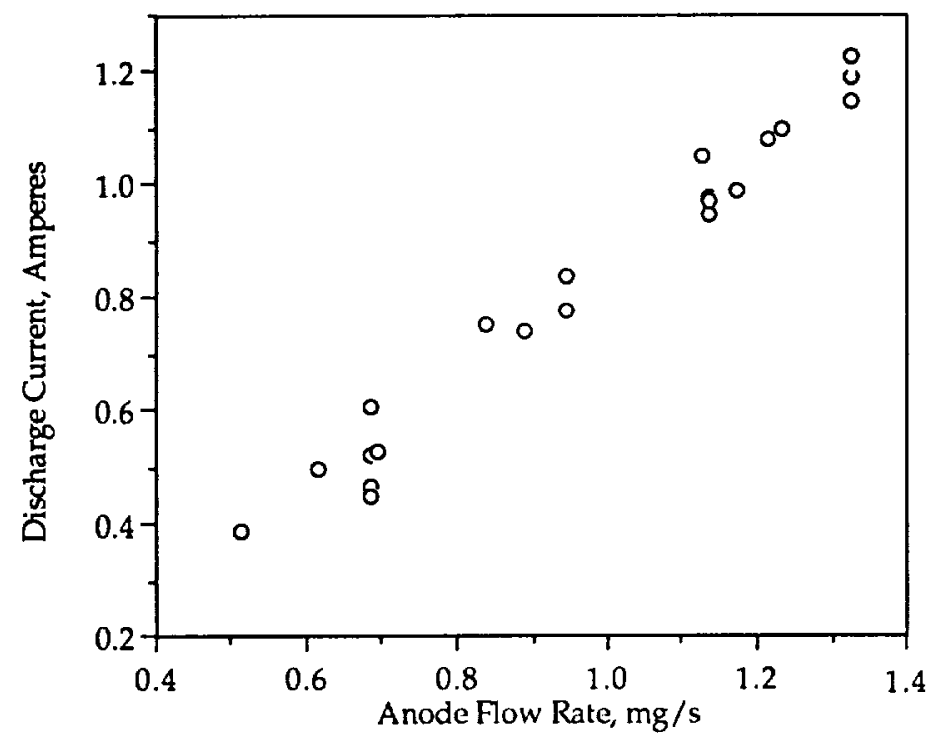

Figure 2: Discharge current versus anode flow rate for the SPT-50.

Figure 3: Thrust versus thruster power for the SPT-50.

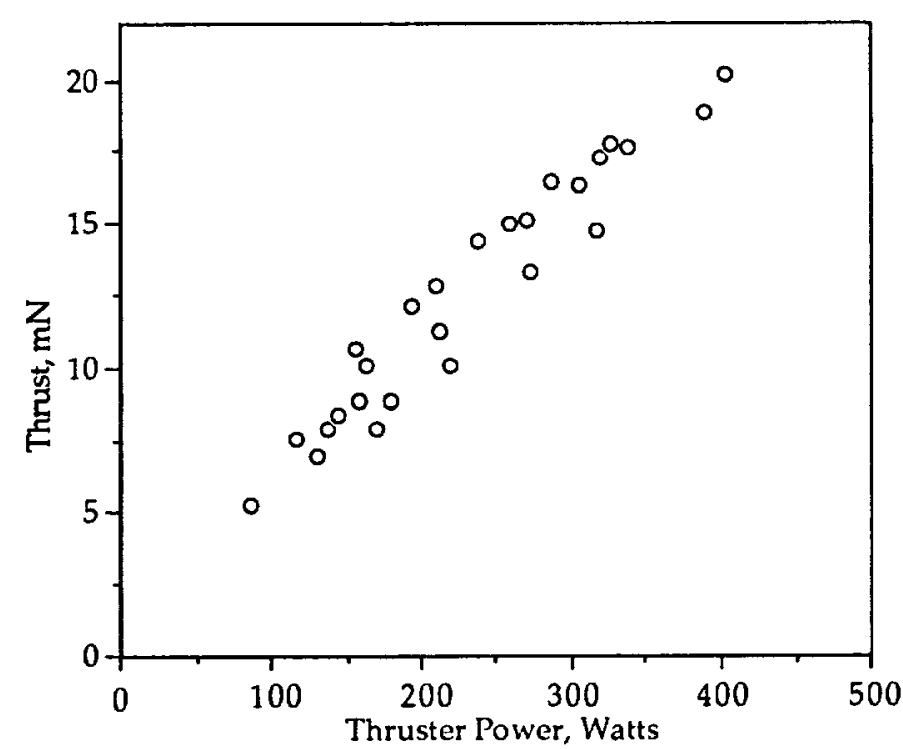

The variation in discharge current at a given anode flow rate shown in Figure 2 was attributed to differences in discharge voltage and non-optimized magnet current settings. As previously discussed by Sankovic, ${ }^{12}$ the optimal operating point can be determined through what is called the principal of current minimization. The inner and outer magnet currents are adjusted to minimize the discharge current for a given discharge voltage and anode flow rate. At some mass flow rates and discharge voltages, the SPT-50 could not easily be optimized in this fashion. In these instances, while adjusting the magnet current, the plasma discharge would self-extinguish and have to be reestablished. If operation at a particular point was problematic this optimization procedure was truncated. As a result, the discharge current could have potentially been reduced further through additional adjustment of the magnet current. Some of the spread in discharge current at a given anode flow rate was attributed to this truncation. The discharge voltage also had a minor effect on the discharge current for a given flow rate, contributing to the spread in discharge current for a given anode flow rate.

As previously stated, the SPT-50 was operated at powers from .09to .4 kilowatts. Both thrust and ion current density distribution were measured in addition to operational parameters. Thruster power included the power dissipated in the magnets, but excluding the cathode heater power. Over this range of powers the engine produced between 5.3 and 20.3 millinewtons of thrust (see Figure 3 ). The differences in thrust for a given power were due to variations in discharge voltage and current. It was possible to obtain a particular thruster power level in multiple ways. For example, a power level can be reached by choosing high current-low voltage operation, low currenthigh voltage operation, or operation at some intermediate combination of current and voltage. Each of these combinations produced a different thrust. In general, the high current-low voltage condition produced the highest thrust. However, the increased thrust obtained at the higher current condition was at the expense of specific impulse and efficiency. A complete set of the data is shown in tabular form in the Appendix. It may be possible to take advantage of the flexibility of SPT operation for certain mission scenarios, i.e. if high thrust was desired for an altitude change and high specific impulse was desired for a station keeping or drag make-up function. 
Functional dependencies of the discharge current on anode flow rate and the variation in thrust with discharge power shown in Figures 2 and 3 suggest the potential impact the xenon feed system has on the performance of low power Hall thruster propulsion systems. Changes in anode flow rate result in changes in discharge current. For the constant voltage PPU discharge supply, this brings about a change in thruster power. For an actively controlled feed system, the propellant feed system can react to changes in environmental conditions or feed pressure and continue to deliver a constant xenon flow rate ensuring constant power operation. Also, with an actively controlled feed system it is possible to change the xenon feed rate and, therefore, power as the power available from the spacecraft degrades. Because passively controlled feed systems can only maintain a flow rate within a certain range, such systems must be capable of tolerating some minimal level of power variation. These data suggest that the variations in thruster power and thrust are measurable for variations in flow rate of even a few percent.

The thruster specific impulse and efficiency determined from the measured performance are plotted in Figure 4 as a function of thruster power. As expected, the performance at the design voltage of 280 volts and the discharge current of 1.05 Amperes was consistent with previously quoted performance data supplied by RIAME. Scatter in the data results from operation at multiple voltage and currents for a given power. Excluding the cathode flow rate, specific impulses in excess of 1600 seconds were demonstrated at efficiencies of about 0.4. Including the cathode flow rate, the specific impulses in excess of 1200 seconds were measured at efficiencies of approximately 0.3. While the effect was not pronounced, the maximum efficiency seemed to occur at discharge current of approximately one Ampere for every discharge voltage. This is most easily seen by considering the data in tabular form as shown in the Appendix.
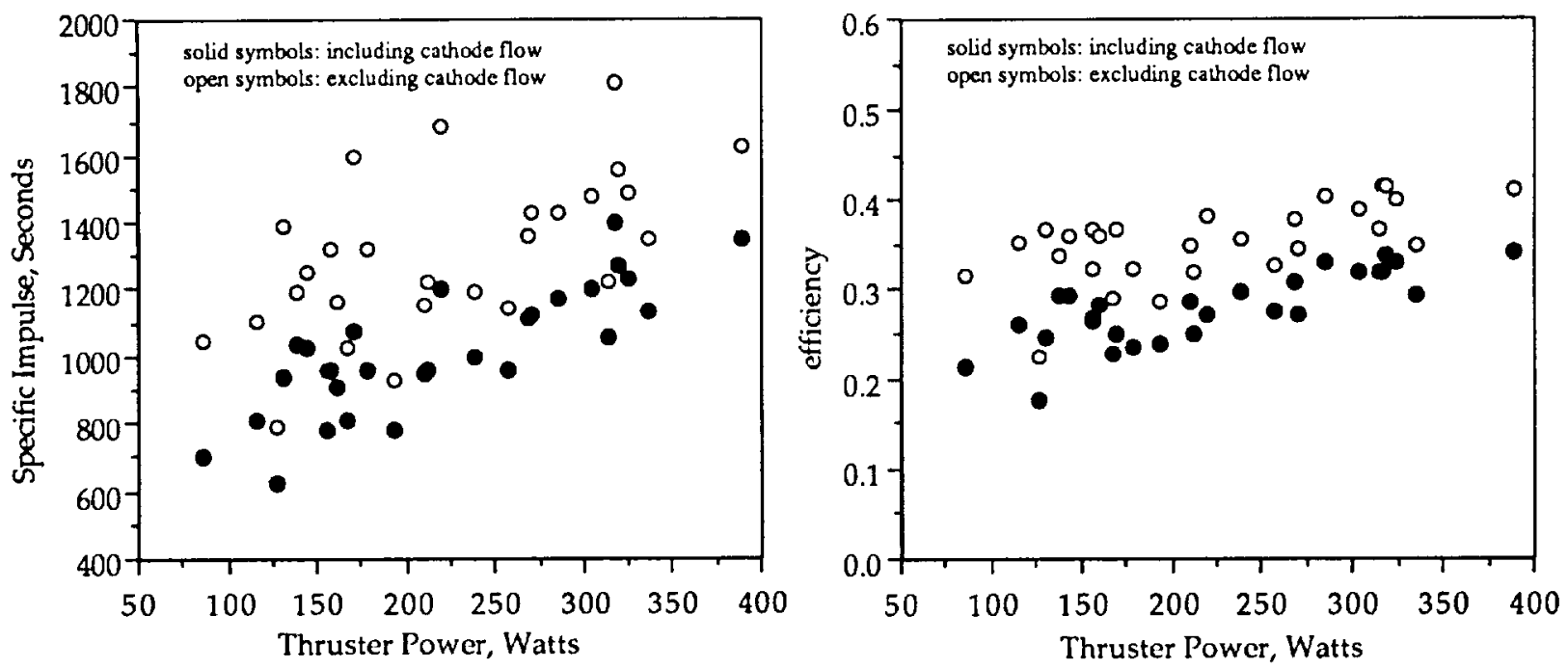

Figure 4: Experimentally determined specific impulse and efficiency versus thruster power for the SPT-50 including and excluding cathode flow rate.

As can be seen from Figure 4 the impact of the cathode flow rate on the specific impulse and efficiency was substantial. Because the xenon that was expelled through the cathode did not produce ions that were accelerated in the discharge chamber, this portion of the propellant flow rate did not significantly increase the thrust produced by the SPT-50. This large effect was primarily the result of using a laboratory cathode for thruster operation that was not developed or optimized for this application. The cathode used required a flow rate of approximately $0.25 \mathrm{mg} / \mathrm{s}$. At the nominal operating point this was $20 \%$ of the anode flow rate and at some lower power operating points the cathode flow rate approached $50 \%$ of the anode flow rate. Cathodes currently being utilized for 1.5 kilowatt class Hall thrusters have a flow fraction of approximately $10 \%$ of the anode flow. Improvements in the cathode technology available for this engine should result in performance approaching that shown in Figure 4 excluding the cathode flow fraction .

The size and shape of the ion beam produced by the SPT-50 during operation was measured using an ion current probe. The measured ion current density distribution is shown in Figure 5 for angles between -100 and 100 degrees. There was some asymmetry in the measured profile with respect to the assigned thruster axis that exceeded the estimated uncertainty in the angular position. The profile was symmetric with respect to the peak value. The high data scatter at large angles was due to experimental uncertainty. As expected, the ion current density was substantially less than that for the higher power SPT-100.32 The maximum ion current density was approximately 0.15 that of the SPT- 100 and the ion current density at 45 degrees, the cant angle 
used for the mission study analysis, the ion current density was 0.2 that for the SPT-100. The determination of a cant angle is based on a maximum acceptable ion flux. This maximum acceptable ion flux will correspond to a particular angular location with respect to the thrust axis. Because the ion flux at all angles was substantially less for the low power Hall thruster than for the higher power Hall thruster, integration of low power Hall thrusters will be much less of an issue with respect to ion impingement.

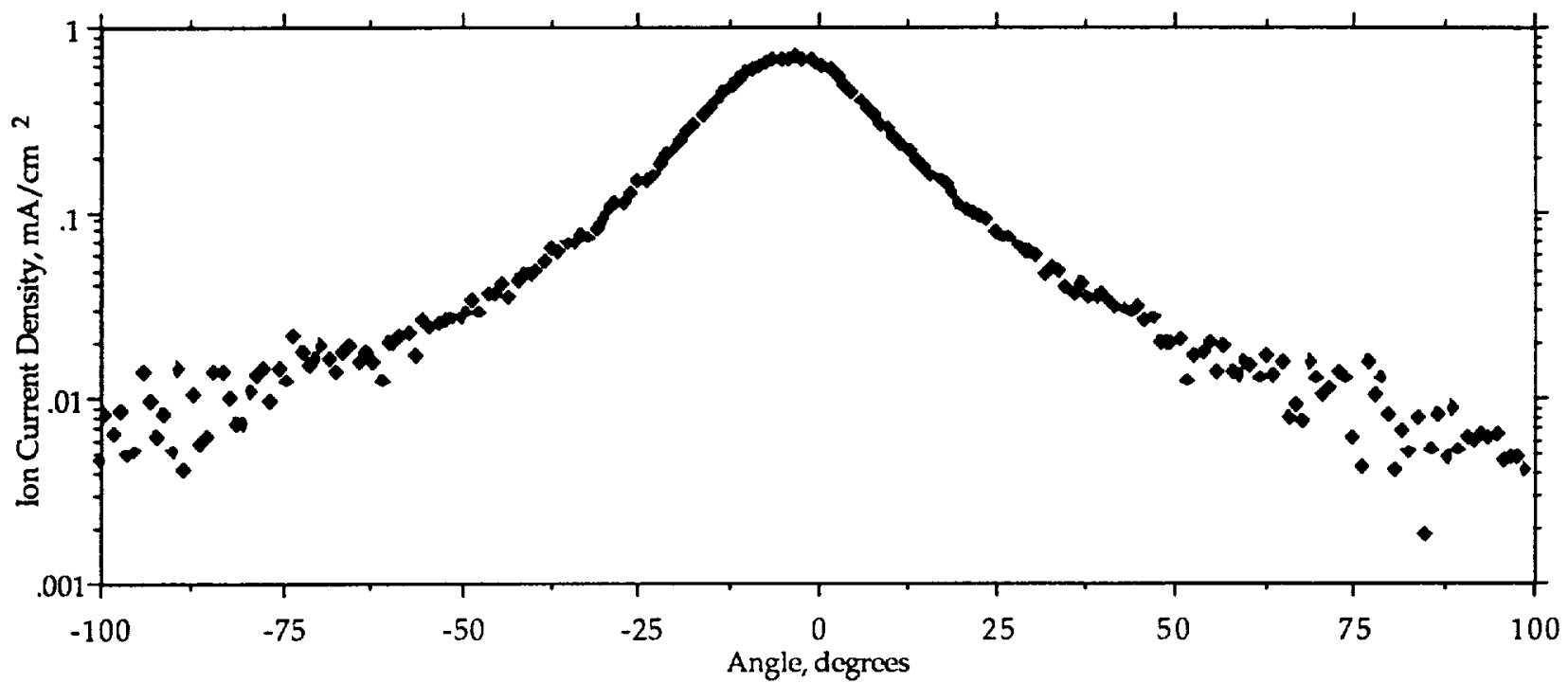

Figure 5: Ion current density distribution measured $60 \mathrm{~cm}$ from the SPT-50 at a background pressure of $1 \times 10^{-5}$ Torr.

\section{Concluding Remarks}

Two separate low power Hall thruster systems were considered: a 0.8 kilowatt system based on the D-38 from TsNIIMASH and a 0.3 kilowatt system based on the SPT-50 from RIAME. Utilizing currently available technology a D-38 propulsion system was proposed that had a system dry mass of 15 kilograms including thermal control, mounting structure and a thruster gimbal. This system had a wet mass of 25.5 kilograms and was capable of providing a total impulse of over 160,000 Newton-seconds. Additional improvements were identified that would result in an advanced D-38 propulsion system. This system had a reduced dry mass and was capable of providing over 320,000 Newton seconds. The benefit of using either system to perform NorthSouth station keeping maneuvers on board a small geostationary satellite was evaluated. The state of the art D-38 propulsion system offered a 54 kilogram mass saving over a 101 kilogram hydrazine monopropellant propulsion system designed to perform the same mission on a 400 kilogram spacecraft. In comparison to a low power arcjet propulsion system, the low power Hall thruster system offered a propulsion system mass reduction of 18.7 kilograms.

The projected SOA 0.3 kilowatt SPT-50 propulsion system had a dry mass of 7.6 kilograms including thermal control, mounting structure and a thruster gimbal. Fueled, the system had a mass of 13.6 kilograms and was capable of providing a total impulse of over 60,000 Newton-seconds. An advanced system was considered that would result in a 6.2 kilogram dry mass and double the total impulse of the SOA system. The potential benefit of flying these systems were evaluated for a 200 kilogram low Earth orbit satellite. The proposed mission required two orbit raises and drag make up for two years. Solar average and solar maximum atmospheric densities were considered for the drag make up calculations. For the solar average atmosphere, the SOA and advanced SPT-50 propulsion systems offered 23 and 28 kilogram mass saving respectively over the 43 kilogram chemical system. For the solar maximum atmosphere, the SOA and advanced SPT-50 propulsion systems offered 40 and 49 kilogram mass saving respectively over the 80 kilogram chemical system. Additionally, the SPT-50 was experimentally evaluated. The SPT -50 was shown to operate stably at thrust levels ranging from 5.3 to 20.3 millinewtons with input powers from .09 to .4 kilowatts. At the 0.3 kilowatt nominal operating point the measured performance agreed with data supplied by RIAME. The effect of anode flow rate on discharge current was evaluated as well as the implication of this on the propellant feed system. The corresponding specific impulses and efficiencies were evaluated as was the size and shape of the ion beam produced during engine operation.

Based on this investigation low power Hall systems based on devices like the TsNIIMASH D-38 or the RIAME SPT-50 offer significant advantages over alternate propulsion systems for certain missions. The systems used in this analysis were projections based on the performance of research class thrusters, components that do not 
currently exist, and other components not optimized for this application. The differences between the proposed flight systems and currently available hardware were considered during this investigation. No technical issues were identified which would prohibit low power Hall thruster systems from being successfully developed in the near future.

\section{References}

1. Trifonov, Y.V., Salikhov, P.S., Avatinyan, G.A., Rylov, Y.P., and Khodnenko, V.P., "VNIIEM Activity in the Field of EP," IEPC-95-10, Sept. 1995.

2. Pidgeon, D. Hoeber, C, and Day, M., "Systems Benefits and Satellite Accomodations of the Stationary Plasma Thruster, SPT-100," AIAA-94-1008, Feb. 1994.

3. Garkusha, V.I., Mironov, S.G., Semenkin, A.V., Grishin, S.D., and Savitsev, V.V., "Electric Propulsion Activity at TsNIIMASH," IEPC-95-9, Sept. 1995.

4. Petrosov, V.A., Baranov, V.I., Vasin, A.I., Wetch, J.R., Britt, E.J., Wong, S.P., and Lin, R.,"A 2000 Hours Lifetime Test Results of a $1.3 \mathrm{~kW}$ T-100 Electric Thruster," IEPC-95-41, Sept. 1995.

5. Clauss, C.W., Tilley, D.L., and Barnhart, D.A., "Benefits of Low-Power Stationary Plasma Thruster Propulsion for Small Satellites," Proceedings of the 9th Annual AIAA/USU Conference on Small Satellites, Logan, Utah, Sept. 1995.

6. Garner, C., Polk, J., and Brophy, J., "Cyclic Endurance Test of a SPT-100 Stationary Plasma Thruster," AIAA-94-2856, June 1994.

7. Sankovic, J.M. and Caveny, L.H., "The BMDO Russian Hall Electric Thruster Technology (RHETT) Program," AIAA-96-2971, July 1996.

8. Randolph, T., Pencil, E., and Manzella, D., "Far-Field Plume Contamination and Sputtering of the Stationary Plasma Thruster," AIAA-94-2855, June 1994.

9. Dickens, J., Mandowski, J., Kristiansen, M., and O'Hair, E., "Impact of Hall Thrusters on Communication System Phase Noise," AIAA-95-2929, July 1995.

10. Brophy, J.R., Barnett, J.W., Sankovic, J.M., and Barnhart, D.A., "Performance of the Stationary Plasma Thruster: SPT-100," AIAA-92-3155, July 1992.

11. Sankovic, J.M., Haag, T.W., and Manzella, D.H., "Operating Characteristics of the Russian D-55 Thruster with Anode Layer," AIAA-94-3011, June 1994.

12. Vince Rawlin, Personal communication, NASA Lewis Research Center, June 1996.

13. Fisher, G., Kozubsky, K., Kahn, J., Kaufman, H., Sokolov, V., Colbert, T., and Day, M., "Design of a High Efficiency Power Processor for the Russian Stationary Plasma Thruster," IEPC-93-043, Sept. 1993.

14. Pinero, L. and Bowers, G.," Power Electronics for a Miniaturized Arcjet," AIAA-96-2961, July 1996.

15. Caveny, L.H., Curran, F.M., Sankovic, J.M., Allen, D.M., Brophy, J.R., and Garner, C., " The BMDO Thruster-on-a-Pallet Program," AIAA-95-2380, July 1995.

16. Rawlin, V.K., and Majcher, G.A., "Mass Comparisons of Electric Propulsion Systems for NSSK of Geosynchronous Spacecraft," AIAA-91-2347, June 1991.

17 Jane's Space Directory, Tenth Edition 1994-1995, Andrew Wilson Ed., Jane's Information Group Inc, Alexandria, VA, 1994.

18. Agrawal, B.N., Design of Geosynchronous Spacecraft, Prentice-Hall, Inc., Englewood Cliffs, NJ, 1986.

19. Myers, R.M., Oleson, S.R., Curran, F.M, and Schneider, S.J., "Small Satellite Propulsion Options," AIAA94-2997, June 1994.

20. Lichon, P.G., McLean, C.H., Vaughn, C.E., and Sankovic, J.M., "Development of a 500 Watt Class Arcjet Thruster System, " IEPC-95-237, Sept. 1995.

21. Oleson, S.R., Myers, R.M., Kluever, C.A., Riehl, J.P., and Curran, F.M, "Advanced Propulsion for Geostationary Orbit Insertion and North-South Station Keeping," AIAA-95-2513, July 1995.

22. Free, B.A., "North-South Stationkeeping with Electric Propulsion Using Onboard Battery Power," COMSAT Laboratories, 1980.

23. Porte, F., Saint Aubert, P., Mawby, D., and Hsing, J., "Application of Ion Propulsion System to Communication Spacecraft," IEPC-93-015, Sept. 1993.

24. Clementine Deep Space Prgram Science Experiement, NASAPublication Number PAM-539, March 1993.

25. Space Mission Analysis and Design, Second Edition, W.J. Larson and J.R. Wertz Eds., Microcosm, Inc., Torrance, CA, 1993.

26. Sankovic, J.M., Hamley, J.A., and Haag, T.W., "Performance Evaluation of the Russian SPT-100 Thruster at NASA LeRC," IEPC-93-094, Sept. 1993.

27. Sankovic, J.M., Haag, T.W., and Manzella, D.H., "Performance Evaluation of a 4.5 kW SPT Thruster, " IEPC-95-30, Sept. 1995.

28. Manzella, D.H. and Sankovic, J.M., "Hall Thruster Ion Beam Characterization," AIAA-95-2927, July 1995. 
Appendix

The following table includes all the SPT-50 thrust measurements taken during this investigation.

Table A1: Performance for the SPT-50. Specific impulses and efficiencies denoted with an asterisk exclude the cathode flow.

\begin{tabular}{|c|c|c|c|c|c|c|c|c|c|}
\hline $\begin{array}{l}\text { Discharge } \\
\text { Voltage }\end{array}$ & $\begin{array}{l}\text { Discharge } \\
\text { Current }\end{array}$ & $\begin{array}{l}\text { Thruster } \\
\text { Power }\end{array}$ & $\begin{array}{l}\text { Anode } \\
\text { flow }\end{array}$ & Thrust & $\begin{array}{l}\text { Specific } \\
\text { Impulse* }\end{array}$ & Efficiency ${ }^{7}$ & $\begin{array}{l}\text { Cathode } \\
\text { flow }\end{array}$ & $\begin{array}{l}\text { Specific } \\
\text { Impulse }\end{array}$ & Efficiency \\
\hline Volts & Amperes & Watts & $\mathrm{mg} / \mathrm{s}$ & $\mathrm{mN}$ & $\mathrm{s}$ & & $\mathrm{mg} / \mathrm{s}$ & $\mathrm{s}$ & \\
\hline 402 & 0.75 & 317 & 0.84 & 14.8 & 1809 & 0.42 & 0.25 & 1398 & 0.32 \\
\hline 401 & 0.50 & 219 & 0.61 & 10.1 & 1687 & 0.38 & 0.25 & 1204 & 0.27 \\
\hline 398 & 0.39 & 170 & 0.51 & 8.0 & 1594 & 0.37 & 0.25 & 1076 & 0.25 \\
\hline 299 & 1.23 & 402 & 1.33 & 20.3 & 1557 & 0.39 & 0.26 & 1304 & 0.32 \\
\hline 302 & 0.97 & 318 & 1.14 & 17.4 & 1559 & 0.42 & 0.26 & 1271 & 0.34 \\
\hline 301 & 0.84 & 270 & 0.94 & 13.3 & 1434 & 0.35 & 0.26 & 1127 & 0.27 \\
\hline 298 & 0.39 & 130 & 0.51 & 7.0 & 1392 & 0.37 & 0.25 & 940 & 0.25 \\
\hline 277 & 1.38 & 389 & 1.26 & 18.9 & 1524 & 0.36 & 0.26 & 1267 & 0.30 \\
\hline 278 & 1.08 & 324 & 1.22 & 17.8 & 1494 & 0.40 & 0.26 & 1233 & 0.33 \\
\hline 281 & 1.05 & 304 & 1.13 & 16.4 & 1483 & 0.39 & 0.26 & 1207 & 0.32 \\
\hline 281 & 0.99 & 285 & 1.17 & 16.5 & 1431 & 0.41 & 0.26 & 1175 & 0.33 \\
\hline 282 & 0.61 & 179 & 0.68 & 8.9 & 1322 & 0.32 & 0.26 & 962 & 0.23 \\
\hline 280 & 0.52 & 157 & 0.68 & 8.9 & 1322 & 0.37 & 0.26 & 962 & 0.27 \\
\hline 281 & 0.47 & 144 & 0.68 & 8.4 & 1252 & 0.36 & 0.15 & 1027 & 0.29 \\
\hline 282 & 0.45 & 138 & 0.68 & 8.0 & 1191 & 0.34 & 0.10 & 1039 & 0.29 \\
\hline 251 & 1.22 & 335 & 1.33 & 17.6 & 1355 & 0.35 & 0.26 & 1135 & 0.29 \\
\hline 249 & 0.98 & 268 & 1.14 & 15.2 & 1365 & 0.38 & 0.26 & 1113 & 0.31 \\
\hline 249 & 0.78 & 213 & 0.94 & 11.3 & 1222 & 0.32 & 0.26 & 960 & 0.25 \\
\hline 199 & 1.19 & 257 & 1.33 & 15.0 & 1151 & 0.33 & 0.26 & 964 & 0.28 \\
\hline 201 & 1.10 & 237 & 1.23 & 14.4 & 1193 & 0.36 & 0.25 & 995 & 0.30 \\
\hline 199 & 0.97 & 210 & 1.14 & 12.9 & 1160 & 0.35 & 0.26 & 946 & 0.29 \\
\hline 201 & 0.74 & 161 & 0.89 & 10.1 & 1164 & 0.36 & 0.25 & 911 & 0.28 \\
\hline 200 & 0.53 & 115 & 0.69 & 7.5 & 1106 & 0.35 & 0.25 & 817 & 0.26 \\
\hline 201 & 0.38 & 86 & 0.51 & 5.3 & 1049 & 0.32 & 0.25 & 708 & 0.21 \\
\hline 151 & 1.15 & 193 & 1.33 & 12.1 & 929 & 0.29 & 0.26 & 778 & 0.24 \\
\hline 153 & 0.95 & 156 & 1.14 & 10.7 & 960 & 0.32 & 0.26 & 783 & 0.26 \\
\hline
\end{tabular}




\begin{tabular}{|c|c|c|c|c|}
\hline \multicolumn{3}{|c|}{ REPORT DOCUMENTATION PAGE } & & $\begin{array}{l}\text { Form Approved } \\
\text { OMB No. 0704-0188 }\end{array}$ \\
\hline \multicolumn{5}{|c|}{ 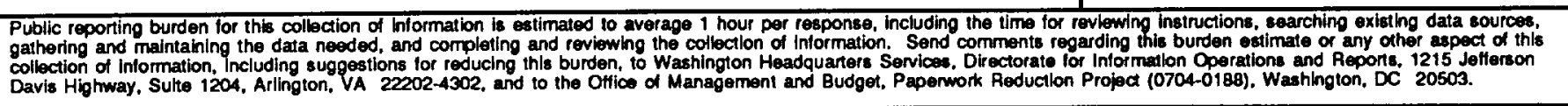 } \\
\hline 1. AGENCY USE ONLY (Leave blank) & \begin{tabular}{r|r} 
א) & REPORT DATE \\
October 1996
\end{tabular} & \multicolumn{3}{|c|}{$\begin{array}{l}\text { 3. AEPORT TYPE AND DATES COVERED } \\
\text { Technical Memorandum }\end{array}$} \\
\hline \multicolumn{3}{|c|}{$\begin{array}{l}\text { 4. TITLE AND SUBTTLE } \\
\text { Evaluation of Low Power Hall Thruster Propulsion }\end{array}$} & \multirow{2}{*}{\multicolumn{2}{|c|}{ 5. FUNDING NUMBERS }} \\
\hline \multicolumn{3}{|c|}{$\begin{array}{l}\text { 6. AUTHOA(S) } \\
\text { David Manzella, Steve Oleson, John Sankovic, Tom Haag, } \\
\text { Alexander Semenkin, and Vladimir Kim }\end{array}$} & & \\
\hline \multicolumn{3}{|c|}{$\begin{array}{l}\text { 7. PERFORMING ORGANIZATION NAME(S) AND ADDRESS(ES) } \\
\text { National Aeronautics and Space Administration } \\
\text { Lewis Research Center } \\
\text { Cleveland, Ohio } 44135-3191\end{array}$} & $\begin{array}{l}\text { 8. PEF } \\
\text { REF }\end{array}$ & $\begin{array}{l}\text { ORMMNG ORGANIZATION } \\
\text { ORT NUMBER }\end{array}$ \\
\hline \multicolumn{3}{|c|}{$\begin{array}{l}\text { 9. SPONSORING/MONITORING AGENCY NAME(S) AND ADDRESS(ES) } \\
\text { National Aeronautics and Space Administration } \\
\text { Washington, D.C. } 20546-0001\end{array}$} & 10. SP & $\begin{array}{l}\text { NSORING/MONITORING } \\
\text { NCY REPORT NUMBEA } \\
\text { SA TM-107326 } \\
\text { A-96-2736 }\end{array}$ \\
\hline \multicolumn{5}{|c|}{$\begin{array}{l}\text { 11. SUPPLEMENTARY NOTES } \\
\text { Prepared for the 32nd Joint Propulsion Conference cosponsored by AIAA, ASME, SAE, and ASEE, Lake Buena Vista, Florida, July 1-3, 1996. } \\
\text { David Manzella and Steve Oleson, NYMA, Inc., 2001 Aerospace Parkway, Brook Park, Ohio } 44142 \text { (work funded by NASA Contract NAS3-27186); } \\
\text { John Sankovic and Tom Haag, Lewis Research Center, Alexander Semenkin, Central Research Institute of Machine Building (TsNIIMASH), } \\
\text { Kaliningrad, Moscow Region 141070 Russia; Vladimir Kim, Research Institute of Applied Mechanics and Electrodynamics, Moscow Aviation } \\
\text { Institute, Moscow 125871 Russia. Responsible person, John Sankovic, organization 5330, (216) 977-7429. }\end{array}$} \\
\hline \multicolumn{3}{|c|}{$\begin{array}{l}\text { 12a. DISTRIBUTHONAVAILABILITY STATEMENT } \\
\text { Unclassified - Unlimited } \\
\text { Subject Category } 20 \\
\text { This publication is available from the NASA Center for AeroSpace Information, (301) 621-0390. }\end{array}$} & \multicolumn{2}{|c|}{ 12b. DISTRIBUTION CODE } \\
\hline \multicolumn{5}{|c|}{$\begin{array}{l}\text { Hall thruster systems based on the SPT-50 and the TAL D-38 were evaluated and mission studies were performed. The } \\
0.3 \text { kilowatt SPT-50 operated with a specific impulse of } 1160 \text { seconds and an efficiency of } 0.32 \text {. The } 0.8 \text { kilowatt D-38 } \\
\text { provided a specific impulse above } 1700 \text { seconds at an efficiency of } 0.5 \text {. The D- } 38 \text { system was shown to offer a } 56 \text { kilo- } \\
\text { gram propulsion system mass savings over a } 101 \text { kilogram hydrazine monopropellant system designed to perform North- } \\
\text { South station keeping maneuvers on board a } 430 \text { kilogram geostationary satellite. The SPT-50 system offered a greater } \\
\text { than } 50 \% \text { propulsion system mass reduction in comparison to the chemical system on board a } 200 \text { kilogram low Earth } \\
\text { orbit spacecraft performing two orbit raises and drag makeup over two years. The performance characteristics of the SPT- } \\
50 \text { were experimentally evaluated at a number of operating conditions. The ion current density distribution of this engine } \\
\text { was measured. The performance and system mass benefits of advanced systems based on both engines were considered. }\end{array}$} \\
\hline \multirow{2}{*}{\multicolumn{3}{|c|}{$\begin{array}{l}\text { 14. SUBJECT TERMS } \\
\text { Stationary plasma thruster; Anode layer thruster; Propulsion systems }\end{array}$}} & & $\begin{array}{c}\text { 15. NUMBER OF PAGES } \\
14\end{array}$ \\
\hline & & & & $\begin{array}{r}\text { 16. PRICE CODE } \\
\text { A03 } \\
\end{array}$ \\
\hline $\begin{array}{l}\text { 17. SECURTY CLASSIFICATION } \\
\text { OF REPORT } \\
\text { Unclassified }\end{array}$ & $\begin{array}{l}\text { 18. SECURTY CLASSIFICATION } \\
\text { OF THIS PAGE } \\
\text { Unclassified }\end{array}$ & $\begin{array}{l}\text { 19. SECURITY CLASSIFICA } \\
\text { OF ABSTRACT } \\
\text { Unclassified }\end{array}$ & ATION & 20. LIMTIATION OF ABSTRACT \\
\hline
\end{tabular}

